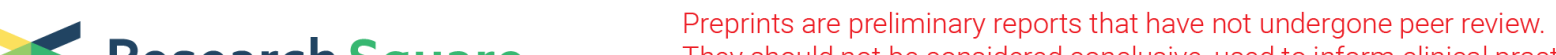 $\begin{array}{ll}\text { Research Square } & \text { They should not be considered conclusive, used to inform clinical practice, } \\ \text { or referenced by the media as validated information. }\end{array}$
}

\section{Optimization The Effect of Roasting Conditions by Central Composite Design (CCD) Method on The Antioxidant Compounds of Opuntia Ficus Indica Seeds From Morocco}

\section{Chakir El Guezzane}

Laboratory of Materials, Nanotechnology and Environment, Faculty of Sciences, Mohammed V University, P.O. Box 1014 Agdal-Rabat, Morocco

\section{Hamza El Moudden}

Laboratory of Materials, Nanotechnology and Environment, Faculty of Sciences, Mohammed V University, P.O. Box 1014 Agdal-Rabat, Morocco

\section{Hicham Harhar}

Laboratory of Materials, Nanotechnology and Environment, Faculty of Sciences, Mohammed V University, P.O. Box 1014 Agdal-Rabat, Morocco

\section{Abdelkader Zarrouk ( $\nabla$ azarrouk@gmail.com )}

Universite Mohammed V de Rabat

\section{Mohamed Tabyaoui}

Laboratory of Materials, Nanotechnology and Environment, Faculty of Sciences, Mohammed V University, P.O. Box 1014 Agdal-Rabat, Morocco

\section{Research}

Keywords: Antioxidant activity, CCD, Opuntia ficus indica, polyphenols, Roasting.

Posted Date: June 29th, 2020

DOl: https://doi.org/10.21203/rs.3.rs-31029/v1

License: (c) (1) This work is licensed under a Creative Commons Attribution 4.0 International License. Read Full License 


\section{Abstract}

The effect of roasting conditions on antioxidant activity Opuntia Ficus Indica seeds from Morocco and their phenolic compounds were optimized by the Central Composite Design (CDD) method. The CCD was used to optimize the roasting conditions: temperature $\left(X_{1}: 60-200{ }^{\circ} \mathrm{C}\right)$ and roasting time $\left(X_{2}: 10-50\right.$ $\mathrm{min})$. The best roasting conditions were used in order to optimize the optimal value of the response : TPC (Total Phenolic Content): X1: $200^{\circ} \mathrm{C}, \mathrm{X} 2: 50 \mathrm{~min}$ with $104.86 \pm 1.94 \mathrm{GAE} / \mathrm{g}$ extract predicted response, TFC (Total Flavonoids Content) : X1: $200{ }^{\circ} \mathrm{C}, \mathrm{X} 2: 50 \mathrm{~min}$ with $81.23 \pm 0.90 \mathrm{mg} \mathrm{QE} / \mathrm{g}$ extract predicted responses, TTC (Total Condensed Tannins Content): X1: $128.9^{\circ} \mathrm{C}, \mathrm{X} 2: 34.92 \mathrm{~min}$ with $6.12 \pm 0.95 \mathrm{mg}$ QAE/g extract) predicted response. Moreover, the optimal potential antioxidant activity by ABTS assay and DPPH assay was found in extracts of Opuntia Ficus Indica seeds roasted: at a high temperature of the roasting. Furthermore, the positive significant correlations were determined by the principal component analysis (PCA) on the one hand, between the antioxidant capacity of the extracts and their antioxidants compounds (TPC and TFC), and on the other hand, between the two assays ABTS and DPPH. Consequently, the results of this work indicated that roasted Opuntia Ficus Indica seeds from Morocco can be considered as an essential ingredient for human foods.

\section{Introduction}

The Opuntia cactus is specie originally from Mexico (Mulas, 1992) and considered an important food for the indigenous populations (Barbera, Inglese, \& Pimienta-Barrios, 1995). It is a specie of the Cactaceae family, the it is distributed in all continents as well as cultivated especially in the arid and semi-arid regions such as Africa and the Mediterranean region, South and Central America (Benayad et al., 2014). Moreover, the prickly pear fruit are rich in sugar, vitamin C, minerals, antioxidant compounds, and pigments, consequently, it was recommended in the human diet (Di Cagno et al., 2016). Furthermore, the seeds from Opuntia sp are considered rich in nutritional value, such as polyphenol, tannins, flavonoids, and fatty acids, in addition to that, the doses of these compounds are higher than in the pulp of the fruit, these fruits are eaten fresh with their seeds (Al Juhaimi et al., 2018). Also, the nutritional value and the chemical compounds of the oils of the seeds can be modified by roasting, this method is considered as a pretreatment which is done before extraction (Gao et al., 2019), and it can render the color, texture, and acceptability of grilled products (Khan \& Saini, 2016). In addition to that, various studies showed that roasting pretreatment modifies the phenolic profile of the seeds; it can improve the health benefit effects (Carciochi, Galván D' Alessandro, Manrique, \& technology, 2016). Consequently, the roasting can influence the antioxidant power of the seeds, this influence can depend on the formation of Maillard reaction products (MRP) and the thermal degradation of natural antioxidant molecules (Açar, Gökmen, Pellegrini, Fogliano, \& Technology, 2009; Zhang, He, Hu, \& technologies, 2011). Also, the study done by Sharma et (Sharma et al., 2015) showed that an increase in phenolic compounds and potential antioxidant capacity of six varieties of onions at $80^{\circ} \mathrm{C}, 100^{\circ} \mathrm{C}$,and $120^{\circ} \mathrm{C}$. In this work, we are interested in the response surface methodology (RMS), it is a statistical technique useful for optimization. It is based on the most important variables and their effects of an experiment to build an empirical model, among the advantages of this 
technique; it makes to reduce the number of experimental tests necessary to evaluate several factors and their interactions (Zhang et al., 2011). In the present work, we want to apply the Central Composite Design (CDD) approach, in order to investigate the effect of roasting treatment: roasting temperature, roasting time to maximize the contents of antioxidants compounds, and the antioxidant activity of opuntia ficus idica seeds. The main objective of this paper, we applied the CDD approach, in order to assess the effect of roasting treatment : roasting temperature and roasting time for to maximize the TPC(Total Phenolic Content),TFC (Total Flavonoids Content ),TTC(Total Condensed Tannins Content), and the antioxidant properties by ABTS and DPPH assays for opuntia ficus indica from Morocco, Significant correlations between the antioxidant compounds and the antioxidant activities of Opuntia ficus-Indica seeds were evaluated by principal component analysis (PCA).

\section{Materials And Methods}

\section{Plant materials}

The plant material (Opuntia ficus-indica seeds) studied, were collected in the period between June and July 2019, in the region of Taza located in the East-North of Morocco.

\section{Preparations of extracts}

After the harvested of the fruits, the seeds were isolated, and then dried in the dark at room temperature for 72 hours, and they have been placed in an aluminum Petri dish ( $7 \mathrm{~cm}$ diameter) and roasted in a forced hot-air convection oven at 60,130 and $200^{\circ} \mathrm{C}$ for 10,30 and 50 min. After that, the seeds will be crushed using a grinder, this fine powder will then be used for the preparation of the various extracts. Moreover, 40 grams of fine powder was macerated with the ethanol solvent for 48 hours. After that, the solvent was evaporated using a rotary evaporator. The extracts obtained are preserved at a temperature of about $-4^{\circ} \mathrm{C}$ until the subsequent analyzes.

\section{Chemicals and reagents}

the chemical reagents that are used in these studies are categorized as follows : 2,2-diphenyl-1-pycridazil (DPPH. 90\%) ,2,2'-azino-bis(3-ethylbenzthiazoline-6-sulphonic acid) (ABTS), Ascorbic acid, 2thiobarbituric acid (TBA), aluminium chloride $\left(\mathrm{AlCl}_{3}\right), \mathrm{K}_{2} \mathrm{HPO}_{4}, \mathrm{KH}_{2} \mathrm{PO}_{4}$, ethylene-diaminetetraacetic acid (EDTA), Sulfuric acid and phenol and potassium persulphate,Folin-Ciocalteu's phenol reagent, aluminum chloride, , sodium acetate, sodium carbonate, sodium hydroxide , methanol, ethanol,ferrous sulfate, ferric chloride, ) and 2,4,6-Tris(1-pyridyl)-5-triazine (TPTZ).

\section{Determination of Total Phenolic Content (TPC)}

The TPC of these extracts seeds was quantified by the method of singleton (Singleton, Orthofer, \& Lamuela-Raventós, 1999). $200 \mu \mathrm{l}$ of OFI seed extracts, add a volume of $1.5 \mathrm{ml}$ of Folin Ciocalteu reagent (diluted 10 times). After 4 minutes, a volume of $1.5 \mathrm{ml}$ of $5 \%$ sodium carbonate $\left(\mathrm{Na}_{2} \mathrm{CO}_{3}\right)$ was added on 
to the solution. The tubes were placed in darkness. After two hours, Gallic acid was used as a standard for the calibration curve. The results were read on a spectrophotometer at $750 \mathrm{~nm}$. The concentration of total polyphenols is deduced according to a calibration interval established with Gallic acid (0-100 $\mu \mathrm{g} /$ $\mathrm{ml})$, as well as are presented in milligrams equivalent of a Gallic acid gram of extract (mg EGA / $\mathrm{g}$ extract).

\section{Determination of Total Flavonoids Content (TFC)}

The TFC was determined according to the method discussed by yeddes et al (Yeddes, Chérif, Guyot, Sotin, \& Ayadi, 2013). $1 \mathrm{ml}$ of extract is added to $1 \mathrm{ml}$ of a solution of $\mathrm{AlCl}_{3}$ ( $2 \%$ in methanol). After ten minutes of reaction, the absorbance is read at $430 \mathrm{~nm}$. The flavonoid content is determined using a linear regression equation deduced from the calibration curve and expressed in milligrams equivalent of Quercetin per gram of extract (mg EQ / g extract). The flavonoid concentration is deduced from a calibration range established with Quercetin $(0-100 \mu \mathrm{g} / \mathrm{ml})$.

\section{Determination of Total Condensed Tannins Content (TTC)}

The TTC was done by the method described by the method described by sun et al (Sun, Ricardo-da-Silva, Spranger, \& chemistry, 1998). $50 \mathrm{~mL}$ of extracts seeds $(50-600 \mathrm{mg} / \mathrm{mL}$ ) was added to $3 \mathrm{~mL}$ of $4 \%$ methanolic vanillin solution and $1.5 \mathrm{~mL}$ of $\mathrm{H}_{2} \mathrm{SO}_{4}$. The absorbance was read at $430 \mathrm{~nm}$ after 15 minutes. The Catechin calibration curve was in the range of $50-600 \mathrm{mg} / \mathrm{mL}$. TTC was presented as $\mathrm{mg}$ Catechin equivalent (CE) per gram of extract

\section{Radical scavenging activity of DPPH1(1-diphenyl picrylhydrazyl)}

The free radical removal capacity of the extracts was evaluated by the method of Grzegorczyk et al (Grzegorczyk, Matkowski, \& Wysokińska, 2007). One ml for each extract at different concentrations (50 to $1000 \mu \mathrm{g} / \mathrm{ml}$ ) was mixed with one $\mathrm{ml}$ of a methanolic solution of DPPH at $0.1 \mathrm{mM}$ and let sit for $30 \mathrm{~min}$ at $27^{\circ} \mathrm{C}$. Methanol and DPPH were used as controls. After incubation at $37^{\circ} \mathrm{C}$ in the dark for $20 \mathrm{~min}$, the absorbance was read at $517 \mathrm{~nm}$. The antiradical capacity was quantified according to the following equation: \% Radical scavenging activity DPPH $=1-\left[A_{\text {sample }} / A_{\text {control }}\right] \times 100$, where $A$ sample and $A$ control were the absorbance of the sample and control. The results obtained for each extract tested are compared with those obtained for ascorbic acid taken as standard antioxidant.

\section{Radical cation inhibition activity (ABTS)}

The radical cation capacity of OFI seed extracts was determined by the method described by Yim el al (Yim et al., 2013). $88 \mu \mathrm{L}$ of $140 \mathrm{mM}$ of potassium persulfate $\left(\mathrm{K}_{2} \mathrm{~S}_{2} \mathrm{O}_{8}\right)$ was added to $5 \mathrm{ml}$ of $7 \mathrm{mM}$ ABTS. ${ }^{+}$ solution. After that, the whole was stored in the dark at room temperature for $16 \mathrm{~h}$. Then,the absorbance of the ABTS ${ }^{+}$mixture was adjusted by ethanol to $0.70 \pm 0.05$ at $734 \mathrm{~nm} .10 \mu$ of OFI seed extracts at different concentration was mixed with $1 \mathrm{ml}$ of ABTS reagent (100 to $1000 \mu \mathrm{g} / \mathrm{ml})$. The absorbance was read against the blank reagent at $734 \mathrm{~nm}$. The inhibition capacity was quantified uation according to the 
following equation:: \% Radical inhibition activity $A B T S=1-\left[A_{\text {extract }} / A_{\text {control }}\right] \times 100$, where $A_{\text {extract }}$ and $A_{\text {control }}$ were the absorbance of the extract and control

\section{Experimental design}

In this study we used the CDD method, this method consists of 11 experimental assays (Table2) was employed for the optimization of roasting variables. The independent variables include roasting temperature and roasting time. These variable had a three levels $(-1.0 .+1)$ which are lower, medium, and higher (Table 1). TPC, TFC and TTC and antioxidant activity by ABTS assay and DPPH assay were selected such as the response of model design $(Y)$ in this study; they are presented in Table 2 . The regression coefficients $(\beta)$ were obtained by the adjustment the experimental results to a second order polynomial model; this model was used to response analysis surface as below.

$$
\mathrm{Y}=\beta_{0}+\sum \beta_{i} X_{i}+\sum \beta_{i i} X_{i}^{2}+\sum \beta_{i j} X_{i} X_{j}
$$

Where, $Y$ is the response variable, $X_{i}$ and $X_{j}$ are the independent variables. $\beta_{0}, \beta_{i,} \beta_{i i}$, and $\beta_{i j}$ are the regression coefficients of the model which are the constant, linear, quadratic ; and interactive effect respectively. These coefficients were obtained by analysis of variance ANOVA using JMP11 (SW) software. The $p$-value of the model, coefficient of determination $\left(R^{2}\right)$, coefficient of adjustment $\left(R^{2}{ }_{\text {adj }}\right)$, and the p-value of lack of fit were used to the estimation of the adequacy of the polynomial equation to the responses. The desirability function was employed for multi-response optimization (Los, Zielinski, Wojeicchowski, Nogueira, \& Demiate, 2019). All terms of the model were significant when their p-value is less than 0.05.3D response surface graphs were generated by JMP11(SW) software (Tomšik et al., 2016).

Table 1

Levels of variables of the roasting condition by CDD

\begin{tabular}{|lllll|}
\hline Extraction process & Independent variables & \multicolumn{3}{l|}{ Level } \\
\cline { 3 - 5 } & & $(-1)$ & $(0)$ & $(+1)$ \\
\hline Maceration process & $\mathrm{X}_{1}$ roasting temperature $\left({ }^{\circ} \mathrm{C}\right)$ & 60 & 130 & 200 \\
\cline { 2 - 5 } & $\mathrm{X}_{2}$ roasting time $(\mathrm{min})$ & 10 & 30 & 50 \\
\hline
\end{tabular}

\section{Data Analysis of principal component analysis (PCA) and matrix correlation}

The correlations between all responses studied (TPC, TFC, TTC, ABTS, and DPPH) were determined by PCA. Also, PCA has represented the eleven extracts studied with the responses in a graph for facilitate comprehension the variation of the results of values photochemical responses according to the nature of the roasting condition.

\section{Data Analysis}


Central Composite Design (CCD) was done to the optimization of roasting conditions for Opuntia Ficus Indica seeds using, it was analyzed by JMP 11(SW) software. Moreover, the XLSTAT 2014 software (Zielinski et al., 2014) was used to determine the Pearson correlation between all data responses and for a graphical representation (PCA). Software IBM SPSS Statistics 21 was used to express the data in means \pm standard error of the mean. The signification of data was done by the Tukey test at alpha $=0.05$.

\section{Results And Discussion}

Table 2 present the results of the responses TPC, TFC, and TTC, DPPH, and ABTS of extracts from opuntia ficus indica seeds. This optimization of the roasting conditions was achieved in eleven randomized trials in order to evaluate the effects of different roasting factures on the studied responses.

Table 2

Experimental design and results of TPC, TFC, TTC, and antioxidant activity by DPPH assay, ABTS assay from opunitia ficus indica seeds extracts

\begin{tabular}{|c|c|c|c|c|c|c|c|}
\hline Run & $x_{1}$ & $x_{2}$ & TPC & TFC & TTC & DPPH IC50 & ABTS IC50 \\
\hline 1 & 130 & 30 & $23.43 \pm 1.23^{a}$ & $\begin{array}{l}53.71 \pm \\
0.90^{\text {ah }}\end{array}$ & $6.8 \pm 0.20^{\mathrm{a}}$ & $217.34 \pm 2.96^{a}$ & $410.62 \pm 4.70^{\mathrm{a}}$ \\
\hline 2 & 200 & 10 & $46 \pm 0.56^{b}$ & $\begin{array}{l}49.14 \pm \\
1.04^{\mathrm{h}}\end{array}$ & $1.2 \pm 0.30^{b}$ & $149.72 \pm 2.89^{b}$ & $287.76 \pm 2.09^{b}$ \\
\hline 3 & 130 & 50 & $41.85 \pm 1.05^{b}$ & $\begin{array}{l}70.21 \pm \\
0.79^{\mathrm{b}}\end{array}$ & $\begin{array}{l}4.6 \pm \\
0.70^{\mathrm{ae}}\end{array}$ & $144.10 \pm 3.03^{b}$ & $320.83 \pm 4.93^{c}$ \\
\hline 4 & 130 & 30 & $2427 \pm 1.20^{\mathrm{a}}$ & $\begin{array}{l}57.21 \pm \\
1.20^{\mathrm{a}}\end{array}$ & $6.4 \pm 0.95^{a}$ & $212.93 \pm 4.03^{\mathrm{a}}$ & $402.92 \pm 3.98^{a}$ \\
\hline 5 & 200 & 30 & $59.86 \pm 0.94^{d}$ & $\begin{array}{l}56.34 \pm \\
0.96^{\mathrm{a}}\end{array}$ & $1 \pm 0.17^{b}$ & $120.30 \pm 2.18^{d}$ & $\begin{array}{l}240.013 \pm \\
3.997^{d}\end{array}$ \\
\hline 6 & 200 & 50 & $\begin{array}{l}104.86 \pm \\
1.94^{\mathrm{e}}\end{array}$ & $81.23 \pm 0.90^{c}$ & $1.4 \pm 0.23^{b}$ & $\begin{array}{l}90.663 \pm \\
2.093^{\mathrm{e}}\end{array}$ & $124.9 \pm 4^{\mathrm{e}}$ \\
\hline 7 & 60 & 10 & $\begin{array}{l}21.57 \pm \\
1.07^{\text {af }}\end{array}$ & $\begin{array}{l}28.86 \pm \\
1.10^{d}\end{array}$ & $0.4 \pm 0.05^{b}$ & $458.69 \pm 3.70^{f}$ & $624.736 \pm 3.11^{f}$ \\
\hline 8 & 60 & 30 & $15.57 \pm 1.10^{f}$ & $\begin{array}{l}30.43 \pm \\
0.43^{\text {de }}\end{array}$ & $\begin{array}{l}1.8 \pm \\
0.33^{\text {be }}\end{array}$ & $\begin{array}{l}375.92 \pm \\
4.98^{g}\end{array}$ & $471.67 \pm 2.90 \mathrm{~g}$ \\
\hline 9 & 130 & 10 & $\begin{array}{l}20.71 \pm \\
0.71^{\text {af }}\end{array}$ & $34.43 \pm 1.03^{\mathrm{e}}$ & $\begin{array}{l}2.1 \pm \\
0.30^{\text {be }}\end{array}$ & $290.47 \pm 3.79^{h}$ & $546.48 \pm 3.21^{i}$ \\
\hline 10 & 60 & 50 & $15.42 \pm 1.02^{f}$ & $\begin{array}{l}63.29 \pm \\
0.90 \mathrm{~g}\end{array}$ & $\begin{array}{l}2.2 \pm \\
0.60^{\text {be }}\end{array}$ & $265.94 \pm 4.02^{i}$ & $367.54 \pm 2.10^{j}$ \\
\hline 11 & 130 & 30 & $26.23 \pm 1.20^{a}$ & $\begin{array}{l}57.89 \pm \\
1.09^{\mathrm{a}}\end{array}$ & $6.1 \pm 0.90^{\mathrm{a}}$ & $215.92 \pm 3.02^{\mathrm{a}}$ & $413.97 \pm 4.02^{\mathrm{a}}$ \\
\hline
\end{tabular}


The data are presented in the form of the average of two individual repetitions $(n=2 e \pm S E M)$, the means followed by similar letters exposing in the same colum are not different $(P<0.05)$. TPC (mgGAE/gextract ) : TFC(mgQE/gextract) : TTC(mgQAE/gextract) : DPPH IC50 $(\mu \mathrm{g} / \mathrm{ml})$ : ABTS IC50 $(\mu \mathrm{g} / \mathrm{ml}), \mathrm{X}_{1}$ roasting temperature $\left({ }^{\circ} \mathrm{C}\right): \mathrm{X}_{2}$ roasting time $(\mathrm{min})$

\section{Interpretation of the response surface model of TPC}

\section{Second-order polynomial model}

In this study, the TPC of extracts from opuntia ficus indica seeds varied from $15.42 \pm 1.02$ to $104.86 \pm$ $1.94 \mathrm{mg} \mathrm{GAE} / \mathrm{g}$ extract. According to the results of ANOVA for TPC (Table 3),the model was significant $(p$-value $<0.0001)$. The lack of fit was not significant $(P$-value $=0.0862)$, which showed that the model equation was adequate to predicting the value values of the response. Additionally, the $\mathrm{R}^{2}$ value was 0.990054 and the adjusted determination coefficient $\left(R_{a d j}{ }^{2}=0.980107\right)$, showing that the model adequately showed the true combination between all factors studied. According to Li et al (LI et al., 2019), when the determination coefficient was more than 0.75 , the model is adequate. The equation Eq. 2 was represented according to a reduced regression model, it can predicate to the effects of factor variables on the content of TPC.

$\mathrm{TPC}=24.093684+26.36 \mathrm{X}_{1}+12.308333 \mathrm{X}_{2}+16.2525 \mathrm{X}_{1 *} \mathrm{X}_{2}+14.445789 \mathrm{X}_{1 *} \mathrm{X}_{1}+8.0107895 \mathrm{X}_{2 *} \mathrm{X}_{2}$ (Eq. 2) 
Table 3

Anova data of the regression coefficient and the terms of the model

\begin{tabular}{|c|c|c|c|c|c|c|}
\hline Source & Coef & $\begin{array}{l}\text { Sum of } \\
\text { square }\end{array}$ & $\begin{array}{l}\text { Degree of } \\
\text { freedom }\end{array}$ & $\begin{array}{l}\text { Mean } \\
\text { square }\end{array}$ & F-value & p-value \\
\hline \multicolumn{7}{|l|}{ TPC } \\
\hline Model & & 7047.1123 & 5 & 1409.42 & 99.5379 & $<.0001 *$ \\
\hline Constant & 24.093684 & & & & & $\begin{array}{l}< \\
0.0001^{*}\end{array}$ \\
\hline$x_{1}$ & 26.36 & 4169.0976 & 1 & 0976. 4169 & 294.4350 & $<.0001 *$ \\
\hline$x_{2}$ & 12.308333 & 908.9704 & 1 & 908.9704 & 64.1944 & $0.0005^{\star}$ \\
\hline$X_{1 *} X_{2}$ & 16.2525 & 1056.5750 & 1 & 1056.5750 & 74.6187 & $0.0003^{*}$ \\
\hline$X_{1 *} X_{1}$ & 14.445789 & 528.6581 & 1 & 528.6581 & 37.3355 & $0.0017^{*}$ \\
\hline$X_{2 *} X_{2}$ & 8.0107895 & 162.5710 & 1 & 162.5710 & 11.4813 & $0.0195^{\star}$ \\
\hline Residual & & 70.7983 & 5 & 14.16 & & \\
\hline $\begin{array}{l}\text { Lack of } \\
\text { fit }\end{array}$ & & 66.669210 & 3 & 22.2231 & 10.7642 & 0.0862 \\
\hline $\begin{array}{l}\text { Pure } \\
\text { Error }\end{array}$ & & 4.129067 & 2 & 2.0645 & & \\
\hline $\begin{array}{l}\text { Total } \\
\text { Error }\end{array}$ & & 70.798277 & 5 & & & \\
\hline $\mathrm{R}^{2}$ & & 0.990054 & & & & \\
\hline $\operatorname{Radj}^{2}$ & & 0.980107 & & & & \\
\hline
\end{tabular}

$X_{1}$ had a significant positive linear effect ( $p$-value $<0.0001$ ), as well as, it's the quadratic $X 1 * X_{1}$ had a significant positive effect ( $p$-value $<0.05$ ) on TPC. Moreover, the linear effect of the roasting time $X_{2}$ and its quadratics effects $X_{2^{\star}} X_{2}$ were shown to have a significant positive effect respectively ( $p$-value $<$ 0.05). Furthermore, the interaction effect between the two parameters studied $X_{1} * X_{2}$ had significant ( $p$ value $<0.05$ ) on TPC.

\section{Response Surface Methodology (RSM) analysis}

The effects of both the roasting temperature and the roasting time and their reciprocal interactions on TPC can be visualized on the generating 3D response surface plots shown in Fig. 1. According to Fig. 1, 
the TPC content increased when $\mathrm{X}_{1}$ roasting temperature $\left({ }^{\circ} \mathrm{C}\right)$ increased at a roasting time fixed, also it increased rapidly when the $X 2$ roasting time ( $\mathrm{min}$ )exceeds $30 \mathrm{~min}$. Thus, the maximal extraction of TPC was found at the strong levels of both the roasting temperature $\left(X_{1}\right)$ and roasting time $\left(X_{2}\right)$. However, to get optimization overall of all variables studied. Optimization of the response was used by desirability function (d) in order to obtain the maximum response in TPC of the opuntia ficus indica seeds, thereby the maximum response precision is obtained when the desirability close to 1 (Figure.6) (Gullian Klanian \& Terrats Preciat, 2017; Laib \& Barkat, 2018; Los et al., 2019). Therefore, the optimal conditions were determined by using the JMP prediction profiler. The results regarding the optimized conditions of roasting by maceration extraction were when the desirability values $(\mathrm{d}=0.89)$ close to 1 (Fig. $6 . \mathrm{a}): 200{ }^{\circ} \mathrm{C}$, $50 \mathrm{~min}$ and predicted response is $101.4711 \mathrm{mg} \mathrm{GAE} / \mathrm{g}$ extract). The experimental value was $104.86 \pm$ $1.94 \mathrm{mg} \mathrm{GAE} / \mathrm{g}$ extract, Therefore, the experimental and predicted responses were close. Hence, these results suggest that the model may be valid for the prevision of phenolic content by extraction maceration of the OFI seeds roasted. These results confirm the results found by several studies. Chandrasekara et al (Chandrasekara, Shahidi, \& Chemistry, 2011) showed that the roasting at high temperature $\left(130^{\circ} \mathrm{C}\right)$ for $33 \mathrm{~min}$ had increased the phenolic content relative to raw seed (testa, cashew nuts).Yu et al (Yu, Ahmedna, \& Goktepe, 2005) have also found that the TPC (in both water and ethanol) from peanut skin was increased about $35.9 \%$ by roasting at $175^{\circ} \mathrm{C}$ for 5 min relative to the raw sample. Also, Locatelli et al (Locatelli et al., 2010) and Yin el al (Yin et al., 2019) respectively indicated that the TPC from extract soluble of hazelnut skin increased at $180^{\circ} \mathrm{C}$ for 20 min more than 10 min,and the TPC increased about 3.4 times at temperature between $120^{\circ} \mathrm{C}$ and $140^{\circ} \mathrm{C}$ for $180 \mathrm{~min}$, as well as, it increases more at $140{ }^{\circ} \mathrm{C}$. Moreover, Kim et al (Kim et al., 2006) showed that, the TPC significantly increased ( $\mathrm{p}$ value $<0.05)$ at heat treatment. Accordingly, the increase in the content of phenolic compounds can be explained by the following causes:

During the roasting ,the molecules phenolic can be degraded/polymerized, which indicated the training of the new compounds, these compounds can be more soluble in ethanol and water, as well as, they can reagent with the Folin-Ciocalteu in alkaline middle(Yu et al., 2005).

It could be due processed by roasting, because the bound molecules bioactive can be released (Jeong et al., 2004).

\section{Interpretation of the response surface model of TFC Second-order polynomial model}

Our results showed that, the TFC of extracts from opuntia ficus indica seeds varied from $28.86 \pm 1.10$ to $81.23 \pm 0.90 \mathrm{mg}$ QE / g extract. Moreover, ANOVA was used to verify the adequacy and the significance of the model. Table 4 showed that, the F-value is large (12. 9938) and the p-value is small (0.0069), which confirms that the model has been validated. Additionally, the lack of fit was not significant ( $p$-value: 0 . 0771) which indicates the was significant for TFC prediction of the opuntia ficus indica seeds roasted, the lack of fit cheks the inability of the model (LotfizadehDehkordi, Ghadimi, \& Metselaar, 2013). The coefficients of determination $R^{2}$ and of adjusted had high values $R^{2}=0.92854$ and $\operatorname{Radj} 2=0.85708$ respectively. These values indicated that the quality of the model is valid. The equation which combines the relationship between the variables and prediction TFC was described below.

$\mathrm{TFC}=52.860526+10.688333 \mathrm{X}_{1}+17.05 \mathrm{X}_{2}-0.585 \mathrm{X}_{1 *} \mathrm{X}_{2}-4.361316 \mathrm{X}_{1 *} \mathrm{X}_{1}+4.5736842 \mathrm{X}_{2} * \mathrm{X}_{2}$ (Eq. 3) 
Table 4

ANOVA data of the regression coefficient and the terms of the model.

\begin{tabular}{|c|c|c|c|c|c|}
\hline Source & Coef & \multicolumn{4}{|c|}{ Sum of squareDegree of freedom|Mean squareF-value $p$-value } \\
\hline Model & & 2510.9388 & 5 & 502.188 & $12.99380 .0069^{*}$ \\
\hline \begin{tabular}{|l|} 
Constant \\
$\mathrm{X}_{1}$
\end{tabular} & $\begin{array}{l}52.860526 \\
10.688333\end{array}$ & 3685.4428 & 11 & 685.4428 & $\begin{aligned}<0.0001^{*} \\
17.73540 .0084^{*}\end{aligned}$ \\
\hline$x_{2}$ & 17.05 & 1744.2150 & 1 & 1744.2150 & $45.13060 .0011^{\star}$ \\
\hline $\mathrm{X}_{1} * \mathrm{X}_{2}$ & -0.585 & 1.3689 & 1 & 1.3689 & \begin{tabular}{l|l}
0.0354 & 0.8581
\end{tabular} \\
\hline$X_{1} * X_{1}$ & -4.361316 & 48.1867 & 1 & 48.1867 & \begin{tabular}{|l|l}
1.2468 & 0.3149
\end{tabular} \\
\hline$X_{2} * X_{2}$ & 4.5736842 & 52.9938 & 1 & 52.9938 & 1.37120 .2944 \\
\hline Residual & & 193.2410 & 5 & 38.648 & \\
\hline Lack of fit & & 183.17941 & 3 & 61.0598 & 12.13720 .0771 \\
\hline Pure Error & & 10.06160 & 2 & 5.0308 & \\
\hline Total Error & & 193.24101 & 5 & & \\
\hline $\mathrm{R}^{2}$ & & 0.92854 & & & \\
\hline $\operatorname{Radj}^{2}$ & & 0.85708 & & & \\
\hline${ }^{*}$ Signi & at $n$ & & & & \\
\hline
\end{tabular}

Roasting time $\left(\mathrm{X}_{2}\right)$ had a positive significant linear effect ( $\mathrm{p}$-value $\left.=0.0011<0.05\right)$ on TFC, and it doesn't have a significant quadratic effect ( $p$-value $=0.2944)$.As well as, the Roasting temperature $X 1$ had significant positive linear ( $p$-value $=0.0084$ ), but its quadratic effect is not significant ( $p$-value $=0.2944$ ). Moreover, the not significant interaction effect between the two parameters studied was observed (Table 4).

\section{Response Surface Methodology (RSM) analysis}

Figure 2 shows the response surface plot of roasting temperature and roasting time on total flavonoid content. The TFC increased with the increased both the roasting time and the roasting temperature. Accordingly, the higher TFC yield was detected in regions of high roasting temperature and hard roasting time. Consequently, the optimum extraction of TFC was at: roasting temperature $200^{\circ} \mathrm{Cand}$ roasting time $50 \mathrm{~min}$, and it was assigned for the predicted response is 80.22623 (mg QE/g extract) with the desirability is $d=0.84$ (Figure.6.b.). Our results are similar with various studies as, Lin et al (Lin et al., 2016) reported that the TFC increased significantly after $5 \mathrm{~min}$ of the roasting, as well as, the flavonoid aglycones and acids are increased according to roasting temperature and time. Furthermore, Kumar et al (Kumar \& Pandey, 2013) mentioned that, the fractions of sugar in flavonoids glycosides have an important role in antioxidants capacity, as well as, the aglcycones had a high effect on the antioxidant capacity more than the glycosides.

\section{Interpretation of the response surface model of TTC Second-order polynomial model}

Table 5 shows the coefficients of regression and their significance for the TTC yield. The regression model was significant $(p$-value $=0.0231)$. Also, the determination coefficients $\left(R^{2}\right)$ for the TTC response variable $(0.881256)$ and the lack-of-fit values $(0.0537)$ were not significant $(P>0.05)$, which indicates that the model can explain all data. So the response variable was included in roasting optimization. Besides, the $\mathrm{R}^{2}$ adjs was 0.762512 ,it indicated that $76.25 \%$ of the variability was estimated by the model. Therefore, the second-order polynomial model was applied (Eq. 4). 
$\mathrm{TTC}=5.8052632-0.133333 \mathrm{X}_{1} 0,75 \mathrm{X}_{2}-0,4 \mathrm{X}_{1 *} \mathrm{X}_{2}-3.463158 \mathrm{X}_{1 *} \mathrm{X}_{1}-1.513158 \mathrm{X}_{2^{\star}} \mathrm{X}_{2}$ (Eq. 4)

Table 5

ANOVA data of the regression coefficient and the terms of the model.

\begin{tabular}{|c|c|c|c|c|c|c|}
\hline \multirow{2}{*}{\multicolumn{7}{|c|}{ Degree of freedom }} \\
\hline & & & & & & \\
\hline Model & & 50.697863 & 5 & 10.1396 & 7.4215 & $0.0231^{*}$ \\
\hline Constant & 5.8052632 & & & & & $0.0002^{\star}$ \\
\hline $\mathrm{X}_{1}$ & -0.133333 & 0.106667 & 1 & 0.106667 & 0.0781 & 0.7911 \\
\hline$x_{2}$ & 0.75 & 3.375000 & 1 & 3.375000 & 2.4703 & 0.1768 \\
\hline $\mathrm{X}_{1} * \mathrm{X}_{2}$ & -0.4 & 0.640000 & 1 & 0.640000 & 0.4684 & 0.5241 \\
\hline $\mathrm{X}_{1} * \mathrm{X}_{1}$ & -3.463158 & 30.383439 & 1 & 30.383439 & 22.2386 & $0.0053^{*}$ \\
\hline$X_{2} * X_{2}$ & -1.513158 & 5.800439 & 1 & 5.800439 & 4.2455 & 0.0944 \\
\hline Residual & & 6.831228 & 5 & 1.3662 & & \\
\hline Lack of fit & & 6.5845614 & 3 & 2.19485 & 17.7961 & 0.0537 \\
\hline Pure Error & & 0.2466667 & 2 & 0.12333 & & \\
\hline Total Error & & 6.8312281 & 5 & & & \\
\hline $\mathrm{R}^{2}$ & & 0.881256 & & & & \\
\hline Radj $^{2}$ & & 0.762512 & & & & \\
\hline \multicolumn{7}{|c|}{$\begin{array}{l}{ }^{\star} \text { Significant at } p<0.05 \\
\text { According to } p \text {-value }<0.05 \text {, the } X_{1} * X_{1} \text { is the quadratic effect of roasting temperature was positive } \\
\text { significant for TTC, on the contrary, its linear effect did not have significant because of the } p \text {-value }= \\
0.791 \text {. As well as, the } X 2 \text { and } X 2 * X_{2} \text { of roasting time were not had significant in TTC because, their } p \text { - } \\
\text { value was respectively: } 0.1768,0.0944 \text {. The } X_{1} * X_{2} \text { had also not significant according to its } p \text {-value was } \\
0.5241 \text {. }\end{array}$} \\
\hline
\end{tabular}

\section{Response Surface Methodology (RSM) analysis}

The 3D of response surface of regression Eq. (3) were constructed using RSM to illustrate the effects of the roasting temperature and roasting time and their interaction on the TTC (Fig. 3). Accordingly, the TTC content increased before the roasting temperature increased at $130^{\circ} \mathrm{C}$, after that it decreased quickly. Also, the TTC increased with the roasting time in the range of 10 to $35 \mathrm{~min}$ and then decreased.. The optimum extraction of TTC was roasting temperature $128.9^{\circ} \mathrm{C}$, roasting time 34.92 min with 5.901 (mg QAE $/ g$ extract) predicted responses and the desirability is $d=0.82$ (Figure.6.c.). These results are similar to these reported by Lin et al (Lin et al., 2016), they showed that, during the roasting at $200{ }^{\circ} \mathrm{C}$ for 20 min the content of condensed tannins from ethanol extracts had a high levels in TTC.

\section{Interpretation of the response surface model of DPPH assay}

\section{Second-order polynomial model}

The ANOVA results from DPPH assay content based on the RSM design are reported in Table 6.The pvalue of the model was $(<0.0001)$, which indicated that the model was significant. Moreover, the $\mathrm{R}^{2}$ and $R^{2}$ adj were 0.997921 and 0.995841 respectively, that confirms the adequacy of the model because $R^{2}>$ 0.75 ( $\mathrm{Ll}$ et al., 2019). Additionally, the lack of fit ( $\mathrm{p}$-value $>0.05$ ) confirms also the adequacy the model for prediction of the antioxidant power for opuntia ficus indica seeds roasted. Therefore, the second-order polynomial model was applied (Eq. 5).

$\operatorname{DPPH}\left(\mathrm{IC}_{50}\right)=217.23774-123.3112 \mathrm{X}_{1}-66.36283 \mathrm{X}_{2+3}+3.42325 \mathrm{X}_{1 \star} \mathrm{X}_{2}+28.110658 \mathrm{X}_{1 \star} \mathrm{X}_{1}-2.714342 \mathrm{X}_{2^{\star}} \mathrm{X}_{2}$ (Eq. 5) 
Table 6

ANOVA data of the regression coefficient and the terms of the model.

\begin{tabular}{|c|c|c|c|c|c|c|}
\hline \multirow{3}{*}{\begin{tabular}{|l|} 
DPPH \\
Model \\
Constant \\
\end{tabular}} & Coef & \multicolumn{4}{|c|}{ Sum of squareDegree of freedomMean of squareF-value } & p-value \\
\hline & & 124190.70 & 5 & 24838.1 & 479.908 & $1<0.0001^{*}$ \\
\hline & 217.23774 & & & & & $<0.0001^{*}$ \\
\hline$x_{1}$ & -123.3112 & 91233.863 & 1 & 91233.863 & 1762.76 & $8<0.0001^{*}$ \\
\hline$x_{2}$ & -66.36283 & 26424.154 & 1 & 26424.154 & 510.552 & $1<0.0001^{\star}$ \\
\hline$X_{1} * X_{2}$ & 33.42325 & 4468.455 & 1 & 4468.455 & 86.3369 & $0.0002 *$ \\
\hline$X_{1} * X_{1}$ & 28.110658 & 2001.863 & 1 & 2001.863 & 38.6788 & $0.0016^{*}$ \\
\hline$X_{2} * X_{2}$ & -2.714342 & 18.665 & 1 & 18.665 & 0.3606 & 0.5743 \\
\hline Residual & & 258.78 & 5 & 51.8 & & \\
\hline Lack of fit & & 248.64531 & 3 & 82.8818 & 16.3558 & 0.0582 \\
\hline Pure Error & & 10.13487 & 2 & 5.0674 & & \\
\hline Total Error & & 258.78018 & 5 & & & \\
\hline$R^{2}$ & & 0.997921 & & & & \\
\hline Radj $^{2}$ & & 0.995841 & & & & \\
\hline${ }^{\star}$ Signifi & at $\mathrm{n}<0$ & & & & & \\
\hline
\end{tabular}

Based on statistical analyses of ANOVA for DPPH, the roasting temperature $\left(\mathrm{X}_{1}\right)$ and roasting time (X2) had a negative significant linear effect on the IC50 of DPPH assay, because their P-value is equal respectively a $<0.0001 *$ and $<0.0001 *$. As well as, their interaction had significant for DPPH because the $p$ value was $0.0002 *$. On the contrary, their quadratic effects were not had significant due to their $p$-value was $>0.005$.

\section{Response Surface Methodology (RSM) analysis}

The response surface (3D) of regression Eq. (5) were constructed using RSM to illustrate the effects of X1 and $X_{2}$ and their interaction $X_{1} X_{2}$ on the $I_{50}$ of DPPH assay (Fig. 4.). We know that the antioxidant power is inversely proportional with the value of the $\mathrm{IC}_{50}$. We observed that the increase in the antioxidant power was made thanks to the increasing of the $\mathrm{X}_{2}$ roasting time and the increasing of the roasting temperature $\left(\mathrm{X}_{1}\right)$. The optimum of the antioxidant power by DPPH assay observed at roasting temperature $200{ }^{\circ} \mathrm{C}$ and roasting time 50 min with $96.60 \%$ of inhibition, which matches $86.3845 \mu \mathrm{g} / \mathrm{ml}$ predicted responses, and also the desirability is $d=0.93$ (Figure.6.d.). Our results confirm those founded by Lin et al (Lin et al., 2016), they reported that, the higher antioxidants capacity was observed at strong roasting temperature for ethanol extracts from almond(Prnus duclis)kernel, and during the roasting at $200{ }^{\circ} \mathrm{C}$ for $20 \mathrm{~min}$ the power for scavenging DPPH radical was strong than the raw sample. Moreover, Chandrasekra et al (Chandrasekara et al., 2011), reported that in their study, the scavenging capacity of DPPH radical increased significantly with the increase of the roasting temperature for soluble phenolic extract from testa, as well as, they justified that increase due to Maillard reaction products MRPs. Indeed, during at roasting, a reaction between the reducing sugars and amino acids can be done, this reaction can produce the new compounds, which are Maillard reaction products MRPs, these formed products can contribute to TPC, flavour, antioxidant activity and color of food (Chandrasekara et al., 2011).

Furthermore, the resultant melanoidin and the intermediate Maillard reaction products (MRPs) had strong antioxidant pwer,which are according to the presence of reductone-type structures (Hayase, Hirashima, Okamoto, Kato, \& Chemistry, 1989). 


\section{Interpretation of the response surface model of ABTS assay \\ Second-order polynomial model}

Experimental modeling results for antioxidant power by ABTS assay were shown in Table 7. From the model analysis, the $\mathrm{R}^{2}$ and $\mathrm{R}^{2}$ adj of the model were $0.99075,0.9815$ respectively, also did not present lack of fit ( $p$-value $=0.0528$ ). Moreover, the model was significant because its $p$-value was $<0.0001$, which showed that the model equation was acceptable to predict the antioxidant power by ABTS assay. this model equation is shown in Eq. 6 as follows:

ABTS $\left(I_{50}\right)=415.29474-135,2122 X_{1}-107.6177 X_{2}+23.584 X_{1 *} X_{2}-68.64034 X_{1 *} X_{1}+9.1731579 X_{2} \times X_{2}(E q 6)$

Table 7

ANOVA data of the regression coefficient and the terms of the model.

\begin{tabular}{|c|c|c|c|c|c|c|}
\hline \multirow{4}{*}{\begin{tabular}{|l|} 
Source \\
ABTS \\
Model \\
Constant \\
$\mathrm{X}_{1}$ \\
\end{tabular}} & Coef & \multicolumn{4}{|c|}{ Sum of squareDegree of freedomMean squareF-value } & p-value \\
\hline & & 193571.35 & 5 & 38714.3 & 107.106 & $1<0.0001^{\star}$ \\
\hline & 415.29474 & & & & & $<0.0001^{\star}$ \\
\hline & -135.2122 & 109693.98 & 1 & 109693.98 & 303.477 & $2<0.0001^{*}$ \\
\hline$x_{2}$ & -107.6177 & 69489.37 & 1 & 69489.37 & 192.247 & $9<0.0001^{\star}$ \\
\hline$X_{1} * X_{2}$ & 23.584 & 2224.82 & 1 & 2224.82 & 6.1551 & 0.0558 \\
\hline$X_{1} * X_{1}$ & -68.64034 & 11935.79 & 1 & 11935.79 & 33.0213 & $0.0022^{*}$ \\
\hline$X_{2} * X_{2}$ & 9.1731579 & 213.17 & 1 & 213.17 & 0.5898 & 0.4772 \\
\hline Residual & & 1807.29 & 5 & 361.5 & & \\
\hline Lack of fit & & 1743.0803 & 3 & 581.027 & 18.0991 & 0.0528 \\
\hline Pure Error & & 64.2050 & 2 & 31.103 & & \\
\hline Total Erro & & 1807.2853 & 5 & & & \\
\hline $\mathrm{R}^{2}$ & & 0.99075 & & & & \\
\hline $\operatorname{Radj}^{2}$ & & 0.9815 & & & & \\
\hline${ }^{\star}$ Signi & ats & & & & & \\
\hline
\end{tabular}

Roasting time $\left(X_{1}\right)$ and roasting temperature $\left(X_{2}\right)$ had a negative significant linear effect $(p<0.05)$. Also, the quadratic effect of the roasting temperature $X 1 * X 1$ had significant effect ( $p$-value $=0.0022)$, and the interaction effect between the two parameters roasting was not significant (Table 7).

\section{Response Surface Methodology (RSM) analysis}

Figure 5 shows the $\mathrm{IC}_{50}$ of $\mathrm{ABTS}$ assay, we observed that the antioxidant power increase significantly when the roasting temperature $X_{1}$ and roasting time $X_{2}$ increased, because the $I_{50}$ decreased. According to, the more $\mathrm{IC}_{50}$ decreases the more the antioxidant power increases. The optimum of the antioxidant power by ABTS assay was at: roasting temperature $200^{\circ} \mathrm{C}$ and roasting time 50 min with $96.75 \%$ of inhibition, which matches $130.581 \mu \mathrm{g} / \mathrm{ml}$ predicted responses, and also the desirability is $\mathrm{d}=0.89$ (Figure.6.e.). These results are similar to several works as Gao et al (Gao et al., 2019) mentioned that, the ABTS capacity was increased significantly during the roasting at $160^{\circ} \mathrm{C}$ for $10 \mathrm{~min}$ compared to raw sample. Also Yin et al (Yin et al., 2019) reported that the ABTS scavenging increased during the heating between $130^{\circ} \mathrm{C}-140^{\circ} \mathrm{C}$ after $60 \mathrm{~min}$.Moreover, these results can depend on several conditions such as, the plants have a bound antioxidant phenol and bound polymeric compounds, during the thermal treatment these molecules can be degraded and released which leads to an increase in the antioxidants activity (Lee, Kim, Kim, Jang, \& chemistry, 2002). Furthermore, after the antioxidants characteristics can be improved thanks to the degradation of the heat-labile antioxidants compounds or training the new 
compounds by Maillard reaction (Nicoli, Anese, Parpinel, \& Technology, 1999). Also, the solubility of nonphenolic molecules was improved by roasting (Dewanto, Wu, Adom, Liu, \& chemistry, 2002).

\section{Comparisons of predict (models) and experimental results.}

The verification experiments for five responses such as antioxidants activity by DPPH IC $50(\mu \mathrm{g} / \mathrm{ml})$, ABTS $\cdot+$ inhibition activityl $\mathrm{C}_{50}(\mu \mathrm{g} / \mathrm{ml})$, Total phenolic Contents (mg GAE/g extract, Total flavonoids (mg QE/g extract), and Total Tannins Content (mg QAE/g extract) were reported in Table 8. These experiments were done at the conditions of responses optimal and in the experimental range. these results showed that the values of responses experimental are close to those predicted.

Table 8: predicted and experimental results at conditions optimal

\begin{tabular}{|l|l|l|l|l|}
\hline $\begin{array}{l}\text { Total phenolic } \\
\text { Contents (mg GAE/g } \\
\text { extract) }\end{array}$ & $\begin{array}{l}\mathrm{X}_{1} \text { roasting temperature } \\
\left({ }^{\circ} \mathrm{C}\right)\end{array}$ & $\begin{array}{l}\mathrm{X}_{2} \text { roasting time } \\
(\mathrm{min})\end{array}$ & $\begin{array}{l}\text { Predicted } \\
\text { value }\end{array}$ & $\begin{array}{l}\text { Experimental } \\
\text { value }\end{array}$ \\
\hline $\begin{array}{l}\text { Total flavonoids content } \\
\text { (mg QE/g extract) }\end{array}$ & $200^{\circ} \mathrm{C}$ & $50 \mathrm{~min}$ & 80.22623 & $81.23 \pm 0.90$ \\
\hline $\begin{array}{l}\text { Total Tannins } \\
\begin{array}{l}\text { Content }(\mathrm{mg} \mathrm{QAE} / \mathrm{g} \\
\text { extract) }\end{array}\end{array}$ & $128.9^{\circ} \mathrm{C}$ & $34.92 \mathrm{~min}$ & 5.901 & $6.12 \pm 0.95$ \\
\hline $\begin{array}{l}\text { Total phenolic } \\
\begin{array}{l}\text { Contents }(\mathrm{mg} \mathrm{GAE} / \mathrm{g} \\
\text { extract) }\end{array}\end{array}$ & $200^{\circ} \mathrm{C}$ & $50 \mathrm{~min}$ & 101.4711 & $104.86 \pm 1.94$ \\
\hline $\begin{array}{l}\text { DPPH IC50 }(\mu \mathrm{g} / \mathrm{ml}) \\
\text { ABTS IC50 }(\boldsymbol{\mu g} / \mathrm{ml})\end{array}$ & $200^{\circ} \mathrm{C}$ & $50 \mathrm{~min}$ & 86.3845 & $90.663 \pm 2.093$ \\
\hline
\end{tabular}

The data are presented in the form of the average of two individual repetitions $(n=2 e \pm S E M)$,

\section{Correlation Matrix}

Table 9 showed the correlations coefficients data between all responses studied. Moreover, Table 10 presents the $\mathrm{p}$-value of these correlation coefficients. Additionally, the DPPH (1/DPPH IC $\left.5_{50}\right)$ and ABTS $\left(1 /\right.$ ABTS $\left.I C_{50}\right)$ represent the power to inhibit DPPH free radical and ABTS. ${ }^{+}$radical respectively.

Table 9

Pearson's correlation matrix coefficient between antioxidant capacity and antioxidants compounds in the extracts from Opuntia Ficus Indica

\begin{tabular}{|c|c|c|c|c|c|}
\hline Variables & TPC & TFC & TTC & $\begin{array}{l}\text { DPPH } \\
\left(1 / \mathrm{DPPH} I \mathrm{C}_{50}\right)\end{array}$ & $\begin{array}{l}\text { ABTS } \\
\left(1 / A B T S ~ I C_{50}\right)\end{array}$ \\
\hline TPC & 1 & & & & \\
\hline TFC & 0.652 & 1 & & & \\
\hline TTC & -0.301 & 0.287 & 1 & & \\
\hline 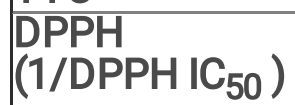 & 0.949 & 0.784 & -0.121 & 1 & \\
\hline $\begin{array}{l}\text { ABTS } \\
(1 / \text { ABTS IC } \\
50)\end{array}$ & 0.966 & 0.727 & -0.255 & 0.920 & 1 \\
\hline
\end{tabular}

The values is bold are different from 0 at a significance level alpha $=0.05 . T P C$ (Total Phenolic Content), TTC :Total Condensed Tannins Content, TFC : Total Flavonoïdes Content, DPPH(1/DPPH IC 50 ): 1,1diphenyl-2-picrylhydrazyl radical scavenging activity;ABTS(1/ABTS IC $\left.{ }_{50}\right)$ 
Table 10

p-values of the correlation matrix coefficient between all variables

\begin{tabular}{|l|l|l|l|l|l|}
\hline Variables & TPC & TFC & TTC & $\begin{array}{l}\text { DPPH } \\
\left(1 / D_{P P H} \text { IC }_{50}\right)\end{array}$ & $\begin{array}{l}\text { ABTS } \\
(1 / \text { ABTS IC }\end{array}$ 50 $)$ \\
\hline TPC & 0 & & & & \\
\hline TFC & 0.030 & 0 & & & \\
\hline TTC & 0.369 & 0.392 & 0 & & \\
\hline $\begin{array}{l}\text { DPPH } \\
\left(1 / D P P H ~ I C_{50}\right)\end{array}$ & $<0.0001$ & 0.004 & 0.723 & 0 & \\
\hline $\begin{array}{l}\text { ABTS } \\
(1 / \text { ABTS IC }\end{array}$ ) & $<0.0001$ & 0.011 & 0.449 & $<0.0001$ & 0 \\
\hline
\end{tabular}

The values is bold are different from 0 at a significance level alpha $=0.05$.

According to Table 9 and Table 10, we observed that, the TPC had high positive correlations significant ( $p$-value < 0.05) between the antioxidants power. The correlation coefficients of TPC were 0.949 and 0.966 with free radical scavenging effect DPPH and ABTS. ${ }^{+}$respectively. These positive correlations are justified that the antioxidants capacity depends on the presence of phenolic compounds in opuntia ficus indica seeds extracts,these results are similar with those reported by several study (Amri et al., 2015;

Cheniany et al., 2013; Guettaf, Abidli, Kariche, Bellebcir, \& Bouriche, 2016). It found that, the TFC had also the positive correlations significant between DPPH (1/DPPH IC 50$)$ and ABTS $(1 /$ ABTS IC 50$)$, these correlation coefficients were 0.784 and 0.727 respectively. Therefore, these results are confirmed by the strong positive correlation significant ( $p$-value $<0.05)$ between TFC and TFC $\left(r^{2}=0.652\right)$. We observed that, the $p$-values of TTC with the antioxidants power were not significant ( $p$-value $>0.05$ ), which indicates that Tannin contribute slightly in this bioactivity. Furthermore, the strong positive correlation significant between tow antioxidant capacity $\left(r^{2}=0.920\right)$,indicates that the same bioactive molecules in our extracts are responsible to the scavenging power of two free radicals DPPH and ABTS. ${ }^{+}$..

\section{Principal Component Analysis (PCA).}

According to Fig. 8, the projections of the responses studied and the experiment assays (extracts) were done by the factorial plan reported in Fig. 8.The cumulative percentage was $95.14 \%$, which indicates that it was is representative of the variables because it was more the $50 \%$. Moreover, the two axe are suitable for explains the all information, with the frits (F1) and second (F2) main components have explained $70.63 \%$ and 24.51 the information respectively. The correlations between all variables studied were explained by a plan formed by F1 and F2 axes. Besides, the F1 axe was formed by the positive correlation between TPC,TFC,ABTS $\left(1 / \mathrm{IC}_{50}\right)$, DPPH $\left.\left(1 / \mathrm{IC}_{50}\right)\right)$, on the contrary the $\mathrm{F} 2$ axe was constructed by TTC (Fig. 7).Ours 11 extracts studied from opuntia ficus indica seeds, were distributed in three groups according the responses (Fig. 8).

Group I:this group was formed by four extracts $(2,3,5,6)$,these extracts had a strong values of the TPC and TFC, as well as, they had also a high power antioxidants by DPPH and ABTS assays.

Group II: it contains four extracts $(1,4,10$, and 11$)$, these extracts are characterized by a strong value of TTC, and by lower values of TPC and TTC. Therefore, their antioxidants activity is lower compared to group I.

Group III is formed by a three extract (7, 8 and 9), these extracts are characterized by the low values of TPC and TFC, and its antioxidant activity is low compared to extracts of the other groups. 
The extracts from Group I are characterized by a high roasting temperature varies between $130^{\circ} \mathrm{C}$ and $200{ }^{\circ} \mathrm{C}$, and a high time of roasting $(50 \mathrm{~min})$ for the extracts roasted at $130^{\circ} \mathrm{C}$, which shows that their a strong antioxidants capacity more than the extracts from the Group II and III obtained by low roasting temperature. Therefore, the roasting makes it possible to increases the extraction of bioactive compounds responsible for antioxidants power.

\section{Conclusion}

Dry thermal processing of seeds from the Opuntia ficus indica increased the amounts of active compounds. As well as, antioxidant activity power was significantly improved in extracts roasted especially at stronger temperature. Furthermore, the results indicated that the temperature and time of roasting had significant effects.PCA showed that on one hand the positive correlation between the photochemical compounds (polyphenol, flavonoids) and the antioxidant capacity (ABTS, $\mathrm{DPPH})$,Consequently, this study showed thermal processing can be used as a pre-treatment to increase the antioxidants capacity of Opuntia ficus Indica seeds.

\section{Abbreviations}

CDD : Central Composite Design; $\mathrm{X}_{1}$ : roasting temperature; $\mathrm{X}_{2}$ : roasting time(min); TPC : Total Phenolic Content; TFC: Total Flavonoids Content; TTC : Total Condensed Tannins Content; PCA: Principal Component Analysis; MRP: Maillard Reaction Products; RMS: Response Surface Methodology; DPPH: 2,2diphenyl-1-pycridazil;ABTS: 2,2'-azino-bis(3-ethylbenzthiazoline-6-sulphonic acid; IC50: half-maximal inhibitory concentration; ANOVA: Analysis of Variance; Eq: equation; $\mathrm{R}^{2}$ : coefficient of determination; $\mathrm{R}^{2}{ }_{\text {adj: }}$ : Coefficient of Adjustment; $\mathrm{d}$ : desirability function; $\mathrm{r}^{2}$ : coefficient of correlation; F1:Frist main component; F2 :Second main component; GI: Group I; GII: Group II; GIli : Group III.

\section{Declarations}

\section{Ethics approval and consent to participate}

Not applicable.

\section{Consent for publication}

Not applicable.

\section{Availability of data and materials}

Not applicable

\section{Competing interests}

The authors declare that they have no competing interests. 


\section{Funding}

Not applicable

\section{Authors' contributions}

C-EG, $\mathrm{H}-\mathrm{H}, \mathrm{A}-\mathrm{Z}$, and $\mathrm{M}-\mathrm{T}$ conceived and designed the experiments. C-EG and $\mathrm{H}-\mathrm{EM}$ have carried out experiments. All authors discussed the results and co-wrote the manuscript. All authors read and approved the final paper.

\section{Acknowledgement}

The authors would thank Dr I. Nounah for helpful discussion along the realization of this work.

\section{References}

1. Açar ÖÇ, Gökmen V, Pellegrini N, Fogliano VJEFR, Technology (2009) Direct evaluation of the total antioxidant capacity of raw and roasted pulses, nuts and seeds. 229(6), 961-969

2. Al Juhaimi F, Özcan MM, Uslu N, Ghafoor K, Babiker EE J. J. o. F. P., \& Preservation (2018) Effect of microwave heating on phenolic compounds of prickly pear (Opuntia ficus-indica L.) seeds. 42(2), e13437

3. Amri O, Elguiche R, Tahrouch S, Zekhnini A, Hatimi AJ J. o. c., \& Research, p. (2015). Antifungal and antioxidant activities of some aromatic and medicinal plants from the southwest of Morocco. $7(7)$, 672-678

4. Barbera G, Inglese P, Pimienta-Barrios E (1995) Agro-ecology, cultivation and uses of cactus pear (Vol. 132): FAO Italy

5. Benayad Z, Martinez-Villaluenga C, Frias J, Gomez-Cordoves C, Es-Safi NE J. I. c., \& products. (2014). Phenolic composition, antioxidant and anti-inflammatory activities of extracts from Moroccan Opuntia ficus-indica flowers obtained by different extraction methods. 62, 412-420

6. Carciochi RA, D' G, Alessandro L, Manrique GD J. I. j. o. f. S., \& technology (2016) Effect of roasting conditions on the antioxidant compounds of quinoa seeds. 51(4), 1018-1025

7. Chandrasekara N, Shahidi FJJ, o. A, Chemistry F (2011) Effect of roasting on phenolic content and antioxidant activities of whole cashew nuts, kernels, and testa. 59(9), 5006-5014

8. Cheniany M, Ebrahimzadeh H, Vahdati K, Preece JE, Masoudinejad A, Mirmasoumi MJAPP (2013) Content of different groups of phenolic compounds in microshoots of Juglans regia cultivars and studies on antioxidant activity. 35(2), 443-450

9. Dewanto V, Wu X, Adom KK, Liu RH J. J. o. a., \& chemistry, f (2002) Thermal processing enhances the nutritional value of tomatoes by increasing total antioxidant activity. 50(10), 3010-3014

10. Di Cagno R, Filannino P, Vincentini O, Lanera A, Cavoski I, Gobbetti MJF m (2016) Exploitation of Leuconostoc mesenteroides strains to improve shelf life, rheological, sensory and functional features 
of prickly pear (Opuntia ficus-indica L.) fruit puree. 59, 176-189

11. Gao P, Cao Y, Liu R, Jin Q, Wang XJ E. j. o. I. s., \& technology (2019) Phytochemical Content, MinorConstituent Compositions, and Antioxidant Capacity of Screw-Pressed Walnut Oil Obtained from Roasted Kernels. 121(1), 1800292

12. Grzegorczyk I, Matkowski A, Wysokińska HJFC (2007) Antioxidant activity of extracts from in vitro cultures of Salvia officinalis L. 104(2), 536-541

13. Guettaf S, Abidli N, Kariche S, Bellebcir L, Bouriche HJDPL (2016) Phytochemical screening and antioxidant activity of aqueous extract of Genista Saharae (Coss. \&Dur.). 8(1), 50-60

14. Gullian Klanian M, Terrats Preciat MJM (2017) Optimization of the ultrasound-assisted extraction of phenolic compounds from Brosimum alicastrum leaves and the evaluation of their radicalscavenging activity. 22(8), 1286

15. Hayase F, Hirashima S, Okamoto G, Kato HJA, Chemistry B (1989) Scavenging of active oxygens by melanoidins. 53(12), 3383-3385

16. Jeong SM, Kim SY, Kim DR, Nam K, Ahn D, Lee SC J. J. o. f. s. (2004). Effect of seed roasting conditions on the antioxidant activity of defatted sesame meal extracts. 69(5), C377-C381

17. Khan A, Saini CJCE (2016) Effect of roasting on physicochemical and functional properties of flaxseed flour. 3(1), 1145566

18. Kim S-Y, Jeong S-M, Park W-P, Nam K, Ahn D, Lee S-C (2006) Effect of heating conditions of grape seeds on the antioxidant activity of grape seed extracts. J F c 97(3):472-479

19. Kumar S, Pandey AK, J. TSWJ (2013) Chemistry and biological activities of flavonoids: an overview. 2013

20. Laib I, Barkat MJF (2018) Optimization of conditions for extraction of polyphenols and the determination of the impact of cooking on total polyphenolic, antioxidant, and anticholinesterase activities of potato. $7(3), 36$

21. Lee J-C, Kim H-R, Kim J, Jang Y-S J. J. o. a., \& chemistry, f (2002) Antioxidant property of an ethanol extract of the stem of Opuntia ficus-indica var. saboten. 50(22), 6490-6496

22. LI H-Z, Tan Y-L, Zhang Z-J, Xia Y-Y, Li X-J, CUI L-X,... Technology (2019) Optimization of ultrasoundassisted extraction of procyanidins from perilla seed hull and their antioxidant activities in vitro. $39(2), 378-387$

23. Lin J-T, Liu S-C, Hu C-C, Shyu Y-S, Hsu C-Y, Yang D-J (2016) Effects of roasting temperature and duration on fatty acid composition, phenolic composition, Maillard reaction degree and antioxidant attribute of almond (Prunus dulcis) kernel. J F c 190:520-528

24. Locatelli M, Travaglia F, Coïsson JD, Martelli A, Stévigny C, Arlorio MJF c (2010) Total antioxidant activity of hazelnut skin (Nocciola Piemonte PGI): Impact of different roasting conditions. 119(4), 1647-1655

25. Los FGB, Zielinski AAF, Wojeicchowski JP, Nogueira A, Demiate IM J. F. a. m. (2019). Extraction optimization of phenolic extracts from carioca bean (Phaseolus vulgaris L.) using response surface 
methodology. 12(1), 148-159

26. LotfizadehDehkordi B, Ghadimi A, Metselaar HS J. J. o. n. r. (2013). Box-Behnken experimental design for investigation of stability and thermal conductivity of TiO 2 nanofluids. 15(1), 1369

27. Mulas M, D'hallewin G, Canu Et, D (1992) Osservazioni sulla radicazione di cladodi di un anno di Opuntia ficus-indica Mill. Rivista di frutticoltura e di ortofloricoltura 54(10):67-70

28. Nicoli M, Anese M, Parpinel MJT, i. FS, Technology (1999) Influence of processing on the antioxidant properties of fruit and vegetables. 10(3), 94-100

29. Sharma K, Ko EY, Assefa AD, Ha S, Nile SH, Lee ET,.. . Analysis D (2015) Temperature-dependent studies on the total phenolics, flavonoids, antioxidant activities, and sugar content in six onion varieties. 23(2), 243-252

30. Singleton VL, Orthofer R, Lamuela-Raventós RM (1999) [14] Analysis of total phenols and other oxidation substrates and antioxidants by means of folin-ciocalteu reagent. In Methods in enzymology (Vol. 299, pp. 152-178): Elsevier

31. Sun B, Ricardo-da-Silva JM, Spranger IJ J. o. a., \& chemistry, f. (1998). Critical factors of vanillin assay for catechins and proanthocyanidins. 46(10), 4267-4274

32. Tomšik A, Pavlić B, Vladić J, Ramić M, Brindza J, Vidović SJUS (2016) Optimization of ultrasoundassisted extraction of bioactive compounds from wild garlic (Allium ursinum L.). 29, 502-511

33. Yeddes N, Chérif JK, Guyot S, Sotin H, Ayadi MTJA (2013) Comparative study of antioxidant power, polyphenols, flavonoids and betacyanins of the peel and pulp of three Tunisian Opuntia forms. 2(2), 37-51

34. Yim HS, Chye FY, Rao V, Low JY, Matanjun P, How SE,.. . technology (2013) Optimization of extraction time and temperature on antioxidant activity of Schizophyllum commune aqueous extract using response surface methodology. 50(2), 275-283

35. Yin Q, Mu H, Zeng M, Gao D, Qin F, Chen J,.. . Characterization (2019) Effects of heating on the total phenolic content, antioxidant activities and main functional components of simulated Chinese herb candy during boiling process. 13(1), 476-486

36. Yu J, Ahmedna M, Goktepe IJF c (2005) Effects of processing methods and extraction solvents on concentration and antioxidant activity of peanut skin phenolics. 90(1-2), 199-206

37. Zhang G, He L, Hu MJ I. f. S., \& technologies, e (2011) Optimized ultrasonic-assisted extraction of flavonoids from Prunella vulgaris L. and evaluation of antioxidant activities in vitro. 12(1), 18-25

38. Zielinski AA, Haminiuk CW, Nunes CA, Schnitzler E, van Ruth SM, Granato, D J. C. r. i. f. s., \& safety, f (2014) Chemical composition, sensory properties, provenance, and bioactivity of fruit juices as assessed by chemometrics: a critical review and guideline. 13(3), 300-316

\section{Figures}






Figure 1

Response surface plots of roasting conditions of TPC of the opuntia ficus indica seeds extracts. 




Figure 2

Response surface plots of roasting conditions of TFC of the opuntia ficus indica seeds extracts. 




Figure 3

Response surface plots of roasting conditions of TFC of the opuntia ficus indica seeds extracts. 


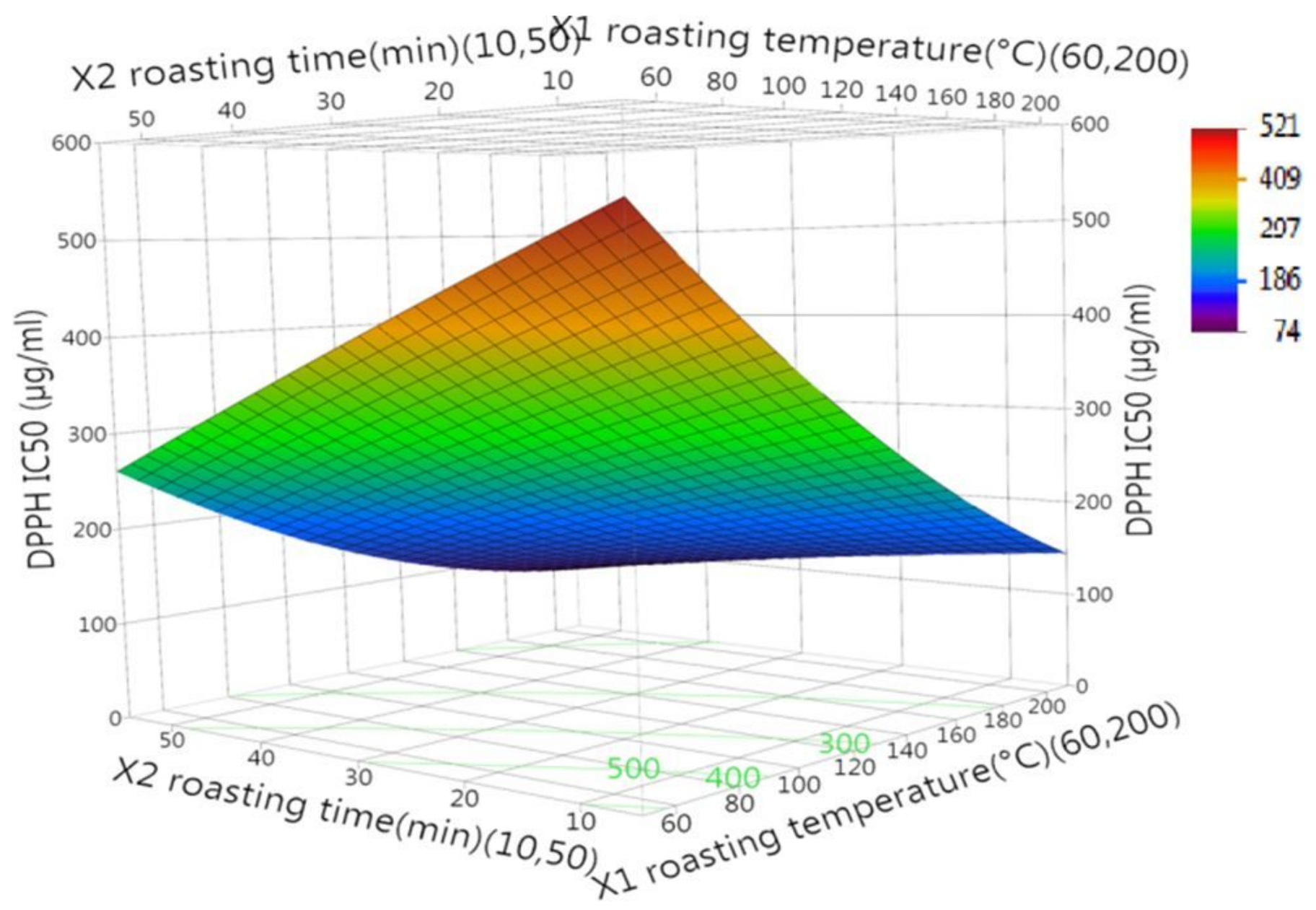

Figure 4

Response surface plots of roasting conditions of DPPH IC50 of the opuntia ficus indica seeds extracts. 


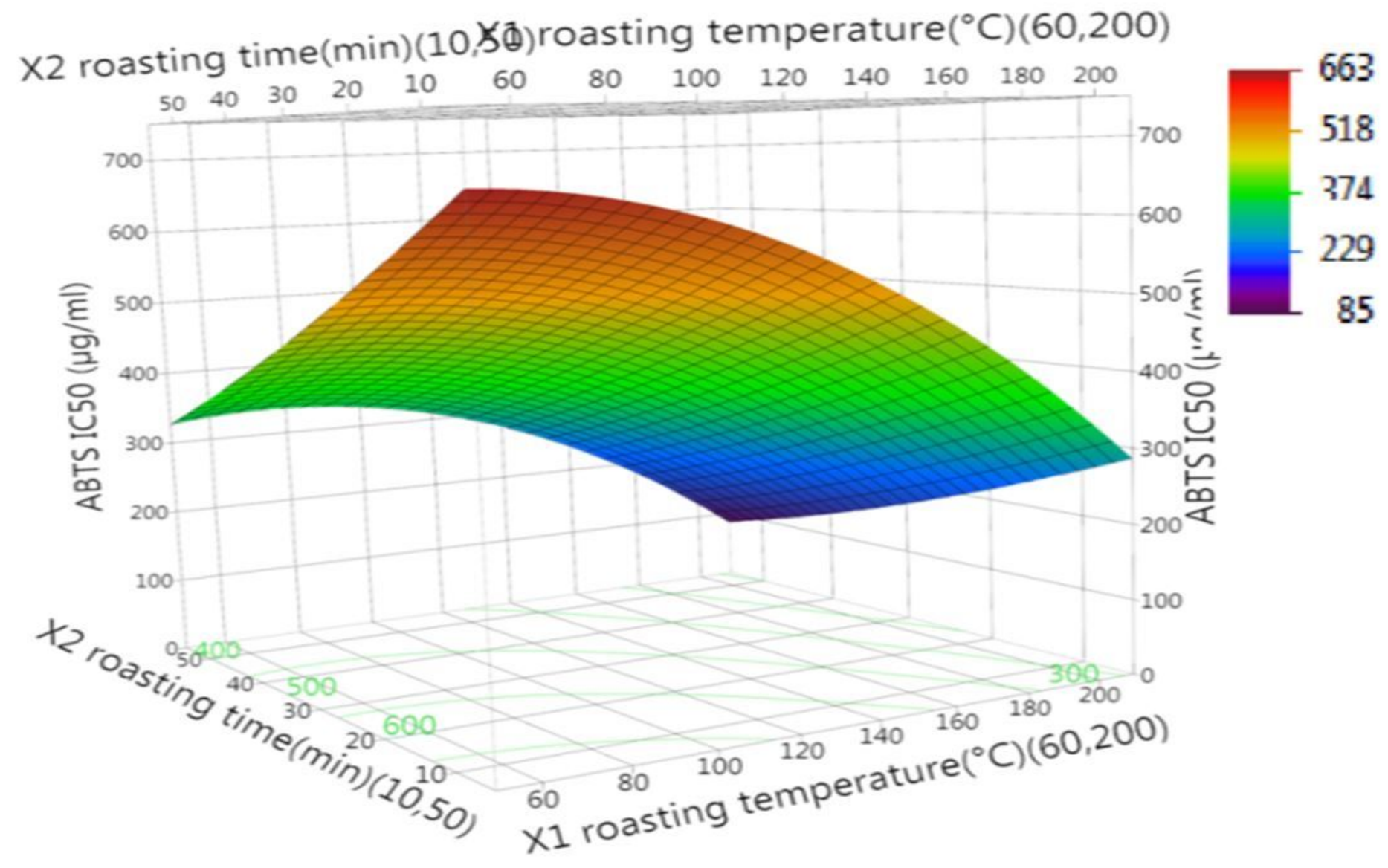

Figure 5

Response surface plots of roasting conditions of ABTS IC50 of the opuntia ficus indica seeds extracts. 




\section{Figure 6}

Desirability results for: a: TPC, b: TFC, c: TTC, d: DPPH, and e: ABTS. 


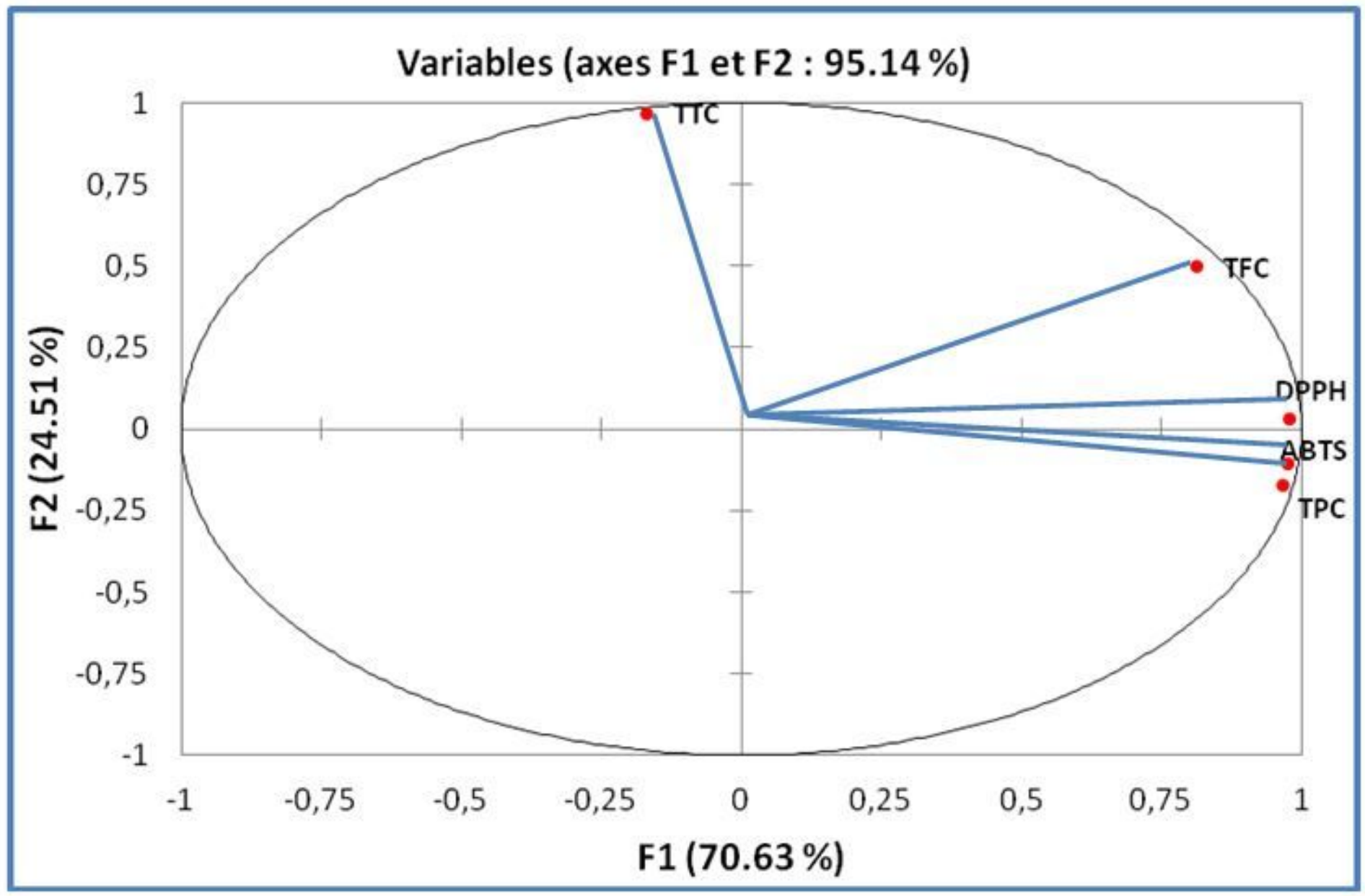

Figure 7

Principal Component Analysis factorial plan carried out on the values (TPC, TFC, TTC, DPPH and ABTS) of the different extracts from Opuntia Ficus Indica DPPH (1/DPPH IC50); ABTS (1/ABTS IC50) 


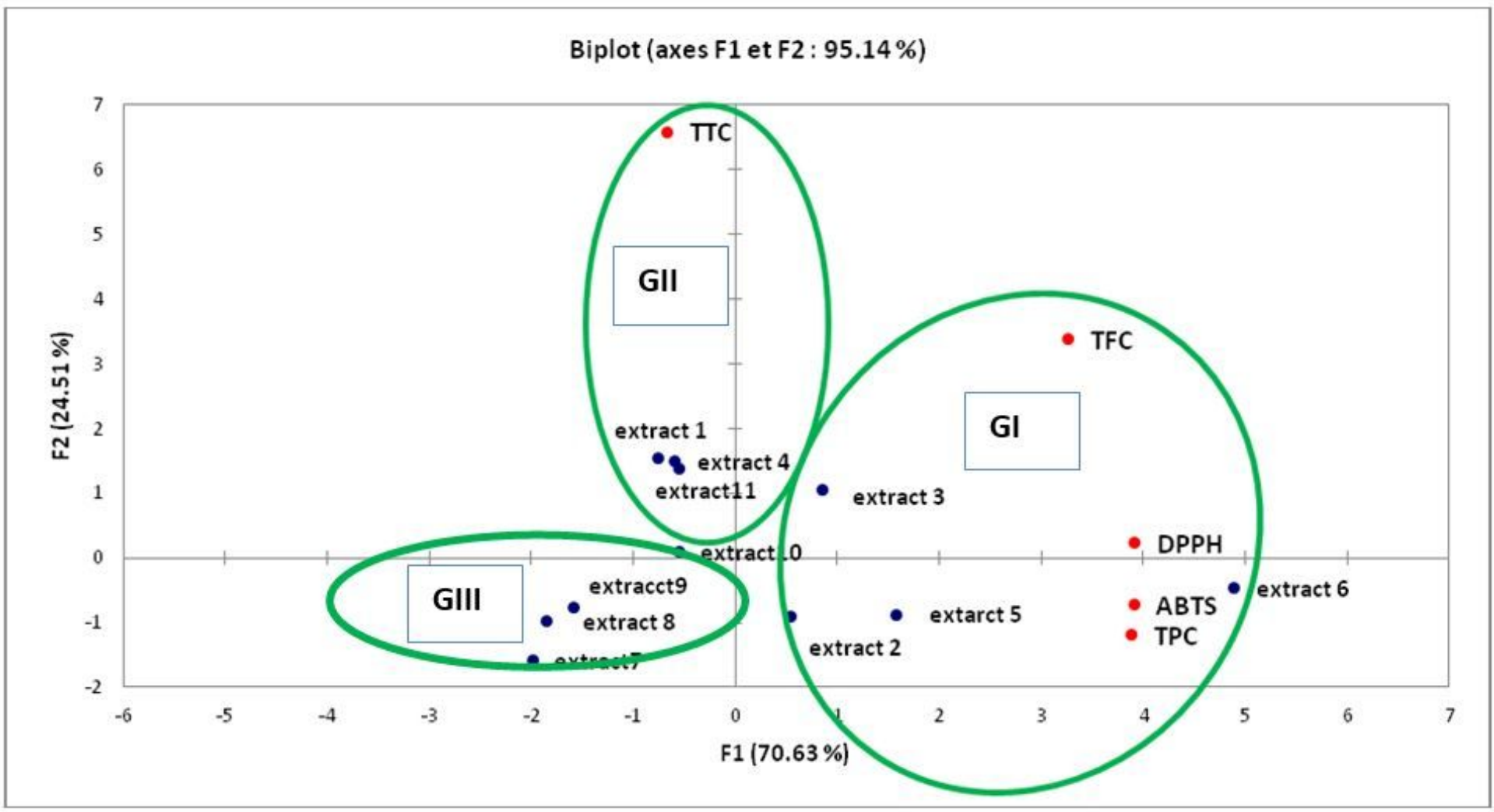

Figure 8

Projection on the factorial plan (F1×F2) of the individual's variable. DPPH (1/DPPH IC50); ABTS (1/ABTS IC50), GI: Group I; GII: Group II; GIIi ;Group III,

\section{Supplementary Files}

This is a list of supplementary files associated with this preprint. Click to download.

- GraphicalAbstract.doc 